\title{
IMPROVEMENT OF PERFORMANCE OF DUAL FUEL ENGINE OPERATED AT PART LOAD
}

\author{
N. Kapilan", T.P. Ashok Babu' ${ }^{1}$ and R.P.Reddy ${ }^{2}$ \\ ${ }^{1}$ Faculty of Mechanical Engineering \\ NITK, Srinivasnagar, Mangalore, 575025, India \\ Phone: +91 - 9845418874, Fax: +91-080-27645990 \\ E-mail: kapil_krecmech@yahoo.com, tpashok@gmail.com \\ ${ }^{2}$ Reva Institute of Technology \& Management, Bangalore, 560 064, India
}

\begin{abstract}
Rising petroleum prices, an increasing threat to the environment from exhaust emissions, global warming and the threat of supply instabilities has led to the choice of inedible Mahua oil (MO) as one of the main alternative fuels to diesel oil in India. In the present work, MO was converted into biodiesel by transesterification using methanol and sodium hydroxide. The cost of Mahua oil biodiesel (MOB) is higher than diesel. Hence liquefied petroleum gas (LPG), which is one of the cheapest gaseous fuels available in India, was fumigated along with the air to reduce the operating cost and to reduce emissions. The dual fuel engine resulted in lower efficiency and higher emissions at part load. Hence in the present work, the injection time was varied and the performance of the dual fuel engine was studied. From the engine tests, it is observed that an advanced injection time results in higher efficiency and lower emissions. Hence, advancing the injection timing is one of the ways of increasing the efficiency of LPG+MOB dual fuel engine operated at part load.
\end{abstract}

Keywords: Alternative fuel, Mahua oil, LPG, diesel engine, performance.

\section{INTRODUCTION}

During recent years, much activity can be observed in the field of alternative fuels due to the depletion of fossil fuels and fluctuations in their price. In the year 2004-2005, India imported $75 \%$ of her petroleum oil from other countries. The demand for diesel and gasoline increased drastically in the 2008-2009. It has been estimated that the demand for diesel will be 66.90 million metric tonnes (MMT) for the year 2011-2012. Hence, the Government of India has taken the necessary steps to fulfill future diesel and gasoline demand and to meet stringent emission norms. Biodiesel and alcohol are being considered as supplementary fuels to petroleum fuels in India. These biofuels are being looked at to provide employment generation for rural people through the plantation of vegetable oils and can be beneficial to sugarcane farmers through the ethanol program (Subramanian et al., 2005). A few researchers have examined the fatty acid profiles of seed oils of 75 plant species having $30 \%$ or more fixed oil in their seed (Mohibbe et al., 2005). They reported that the fatty acid methyl esters of oils of 26 species were found most suitable for use as biodiesel and meet the major specification of biodiesel standards of the USA, Germany and Europe.

In the transportation sector, a large number of investigations have been carried out internationally in the area of vegetable oils as fuel. A researcher listed over 350 oil- 
bearing crops (Jamieson, 1974) while other researchers identified 70 species of oil seeds with considerable potential (Duke and Bagby, 1982). The interest in using vegetable oils as alternative fuels originated within the agricultural community as a fuel for agricultural tractors and equipment (ASAE, 1982). Several studies (Deepak et al., 2008; Mariusz and Geottle, 1992; Ramadhas et al., 2004, 2005) have shown that chemically unaltered vegetable oils are not suitable as a fuel for diesel engines.

'Mahua' is the name for a medium to large tree belonging to the sapotaceae family. The tree may attain a height of up to 20 meters. Mahua is a slow growing species, attains a mean height of 0.9 to $1.2 \mathrm{~m}$ at the end of its fourth year. As a plantation tree, Mahua is an important plant having vital socio-economic value. This species can be planted on roadside, canal banks, etc., on a commercial scale and in social forestry programmes, particularly in tribal areas. The seed and oil potential of the mahua tree in India is 0.5 and 0.18 MMT respectively. The fresh oil from properly stored seed is yellow in colour (Bringi, 1987). Mahua seeds are shown in Figure 1.

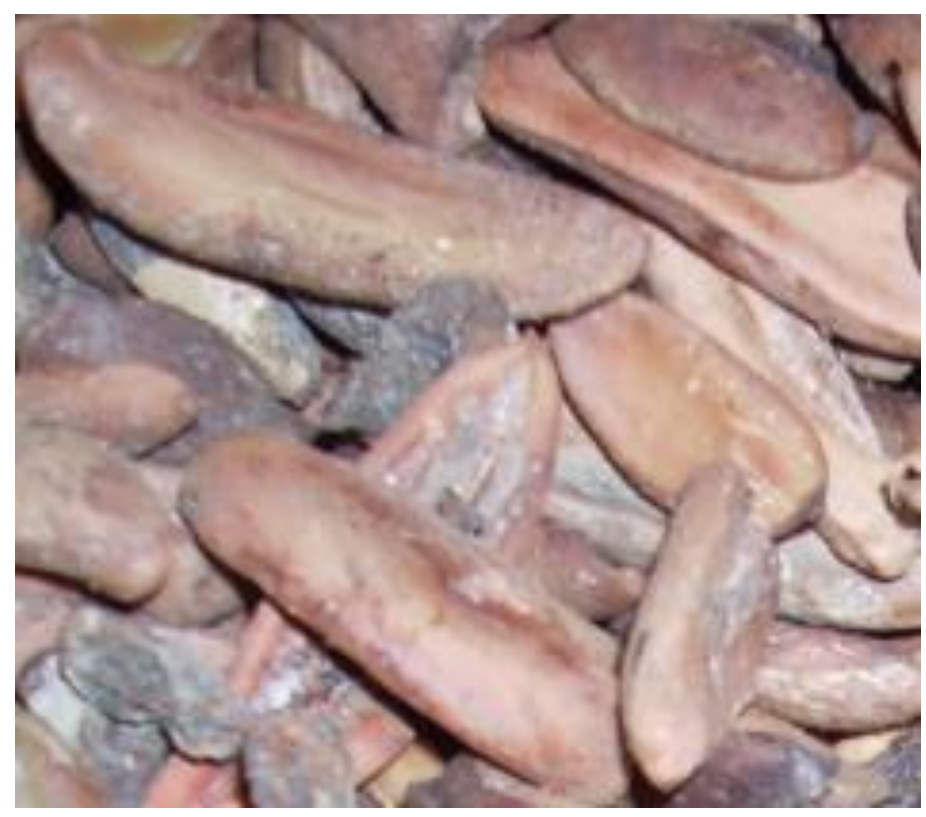

Figure 1. Mahua seeds

Researchers (Raheman and Ghadge, 2007; Puhan et al., 2005) have reported that the biodiesel derived from Mahua oil (MO) can be used as sole fuel or blends with diesel in diesel engines, with considerable reduction in $\mathrm{CO}$, UBHC and smoke emissions and slightly higher NOx emission. From the literature (Monyem et al., 2001; Nwafor, 2005; Manieniyan and Sivaprakasam, 2008; Banapurmath et al., 2009; Sahoo et al., 2009), it is observed that injection timing is one of the variables which affect the performance and emissions of diesel engines. Hence in the present work, the injection timing was advanced and its effect on engine performance was studied.

In India biodiesel is costlier than diesel and hence fumigation of low emission and cheaper gaseous fuels is one of the ways of reducing the operating cost. Hence the main objective of this experimental study is to study the effect of fumigation of LPG on the performance and emissions of Mahua oil biodiesel operated diesel engine at part load and to study the effect of injection timing. The injection timing was varied by introducing shims between the body and head of the fuel injection pump. 


\section{MATERIALS AND METHODS}

The double filtered and refined MO was converted into biodiesel by transesterification using methanol and sodium hydroxide. Table 1 shows the characteristics of MO.

Table 1. Characteristics of MO

\begin{tabular}{lc}
\hline \multicolumn{1}{c}{ Property } & Value \\
\hline Refractive Index & 1.456 \\
Saponification Value & 190 \\
Iodine Value, (g of $\mathrm{I}_{2} / \mathrm{g}$ of oil) & 59 \\
Unsaponifiable matter, $(\%)$ & 1.3 \\
Colour & Dark Yellow \\
\hline
\end{tabular}

\section{Biodiesel production}

In the present work, the transesterification reaction was performed in a round bottom vessel of $500 \mathrm{~mL}$ in volume. First, the reactor vessel was filled with $210 \mathrm{~mL}$ of MO. Then, a measured amount of the methanolic sodium hydroxide, which was prepared by dissolving $2 \mathrm{~g}$ of sodium hydroxide in $85 \mathrm{~mL}$ of methanol, was added to the reactor. For refluxing purpose, a vertical water cooled condenser was used. A hot plate cum magnetic stirrer was used for heating and stirring the reactants. The reactor was immersed in a constant temperature water bath which was maintained at $60 \mathrm{C}$. The transesterification reaction was carried out for two hours. After transesterification, the condenser was removed and the products were heated, to remove excess methanol. After heating, the products were shifted to a $500 \mathrm{~mL}$ separator funnel, for phase separation. The top layer containing methyl esters of Mahua oil (biodiesel) were washed with warm water, to wash out impurities such as soap and other residues. Finally the biodiesel was dried using $5 \mathrm{gm}$ of anhydrous sodium sulphates. The transesterification setup and products of transesterification in the separating funnel are shown in Figure 2.

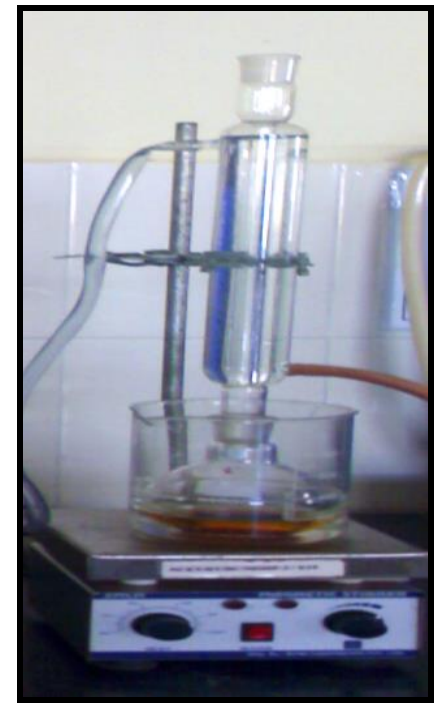

Figure 2. (a) Transesterification setup

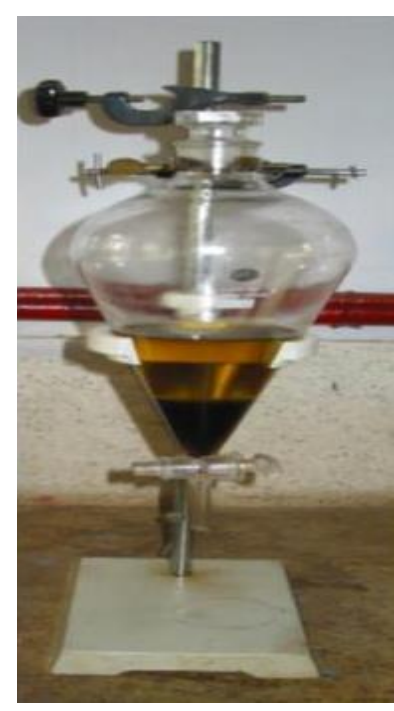

(b) Separating funnel 


\section{Engine Test Instrumentation}

The engine tests were conducted on a single cylinder, four stroke, direct injection, compression ignition, diesel engine. An eddy current dynamometer was used for loading the engine. The engine speed was sensed by an inductive pick up sensor and indicated by a digital rpm indicator, which is a part of an eddy current dynamometer. The liquid fuel flow rate was measured on the volumetric basis using a burette and a stopwatch. An AVL make smoke meter was used to measure the smoke and an MRU make exhaust gas analyser was used for the measurement of emissions. A chromel alumel thermocouple in conjunction with a digital temperature indicator was used for measuring the exhaust gas temperature. The entire instrumentation is interfaced with the computer. The schematic of the test setup is shown in Figure 3. The total uncertainty for the engine experiments is calculated (Holman, 2006) and is equal to $\pm 2.045 \%$.

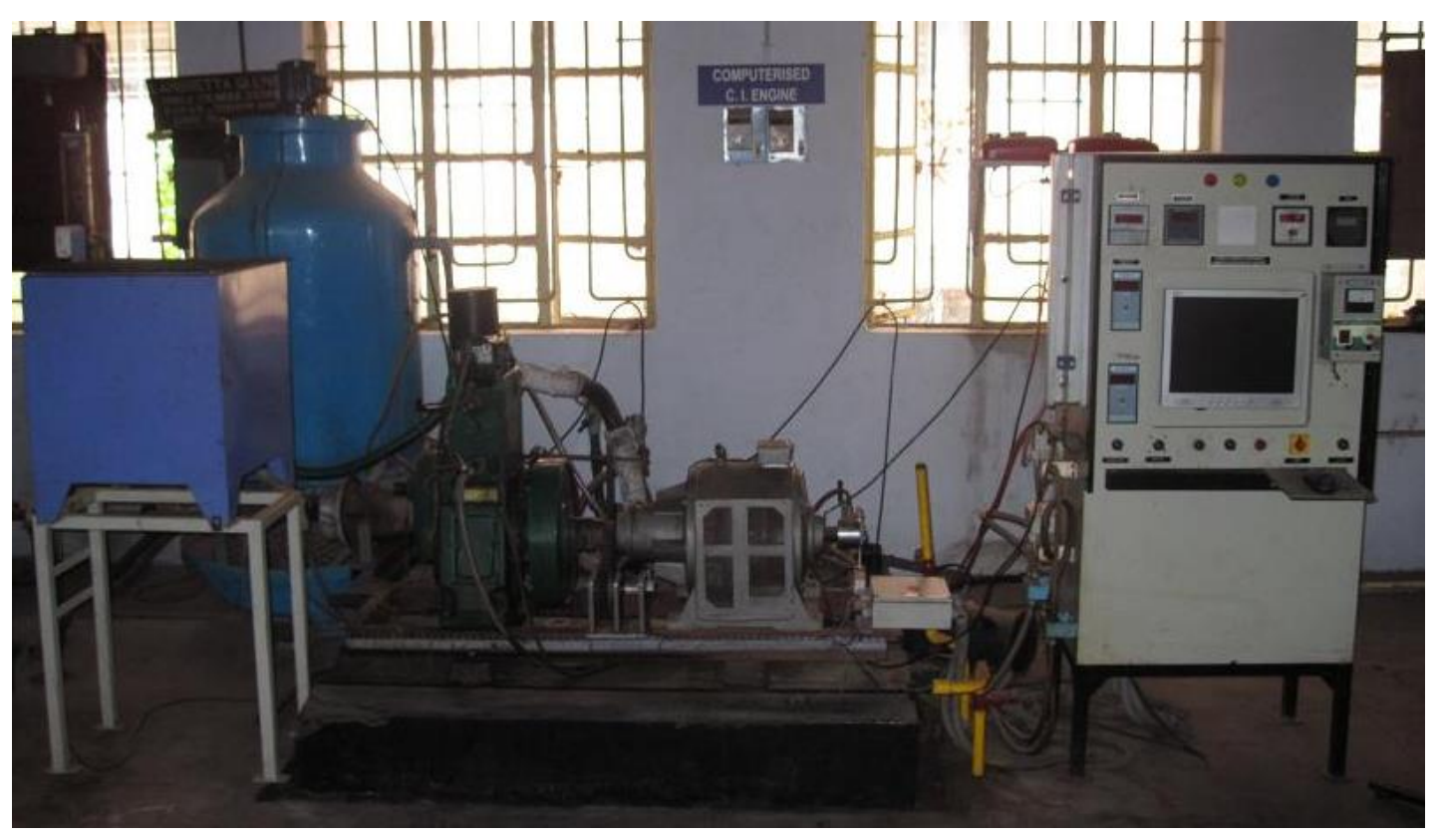

Figure 3. Engine experimental setup

The engine tests were initially carried out on the engine using diesel and MOB as the fuel and at the standard injection time of $24^{\circ} \mathrm{bTDC}$, to provide the base line data. Then the engine was modified to work in dual fuel by incorporating an LPG fuel tank, control valve, rotameter, flame trap and gas carburetor to the cylinder. In dual fuel mode, the engine was started with MOB as sole fuel and the load was gradually increased to $50 \%$ of the full load. Then the LPG was fumigated along with the air and the LPG flowrate was maintained constant, using the control valve. The LPG flowrate was varied up to the maximum value such that the engine does not knock. Each engine test was repeated three times. The values given in this study are the average of these three results. After the engine tests at the injection time of $24^{\circ} \mathrm{bTDC}$, the injection time was advanced to $27^{\circ}$ and $30^{\circ}$ bTDC using shims. The brake power of the engine was calculated by measuring the engine speed and torque. The fuel consumption per hour was calculated by measuring fuel consumed per unit time. From the brake power and 
fuel consumption, the brake thermal efficiency of the engine was determined. The details of the engine are given in Table 2.

Table 2. Engine specifications

\begin{tabular}{ll}
\hline Engine & $\begin{array}{l}\text { Single cylinder, four stroke, water } \\
\text { cooled, diesel engine }\end{array}$ \\
\hline Make / model & Kirloskar / AV1 \\
Rated power & $3.7 \mathrm{~kW} \mathrm{@} \mathrm{1500} \mathrm{rpm}$ \\
Bore X Stroke & $87.5 \mathrm{X} 110 \mathrm{~mm}$ \\
Compression ratio & $16.5: 1$ \\
Type of combustion chamber & Hemispherical shape bowl in piston \\
Rated speed & $1500 \mathrm{rpm}$ \\
Governor & Mechanical governing (centrifugal \\
& type) \\
Aspiration & Naturally aspirated \\
Fuel injection system & Single barrel fuel injection pump \\
& and inline fuel injector \\
\hline
\end{tabular}

\section{RESULTS AND DISCUSSION}

The fuel properties of MO, MOB and diesel were determined according to ASTM standard test procedure and are shown in Table 3. It is observed that the properties of MOB are close to those of diesel and satisfy the biodiesel standards of many countries. The flash point, pour point and viscosity of the MO were higher than those of MOB and diesel. The viscosity of the MOB is 1.8 times higher than that of diesel. The calorific value of the MOB is lower than that of diesel due the presence of oxygen in the molecular structure of the MOB.

Table 3. Properties of MO, MOB and diesel

\begin{tabular}{lcccc}
\hline \multicolumn{1}{c}{ Property } & ASTM D6751-02 & MO & MOB & Diesel \\
\hline Flash point, $\left({ }^{\circ} \mathrm{C}\right)$ & $\mathrm{D} 93$ & 212 & 129 & 56 \\
Cloud point, $\left({ }^{\circ} \mathrm{C}\right)$ & $\mathrm{D} 2500$ & 9 & 2 & -20 \\
Calorific Value, $(\mathrm{kJ} / \mathrm{kg})$ & - & 35614 & 36914 & 42960 \\
Kinematic Viscosity at $40^{\circ} \mathrm{C}$, & $\mathrm{D} 445$ & 27.63 & 4.85 & 2.68 \\
$\left(\mathrm{~mm}^{2} / \mathrm{sec}\right)$ & & & & \\
Density at $15{ }^{\circ} \mathrm{C},\left(\mathrm{kg} / \mathrm{m}^{3}\right)$ & $\mathrm{D} 1298-99 \mathrm{R} 05$ & 915 & 883 & 846 \\
Carbon residue, $(\%)$ & $\mathrm{D} 4530$ & 0.43 & 0.01 & 0.01 \\
Copper corrosion & $\mathrm{D} 130$ & - & 1 & 1 \\
Cetane number & $\mathrm{D} 613$ & - & 49 & 48 \\
Acid number, $(\mathrm{mg} \mathrm{KOH} / \mathrm{g})$ & $\mathrm{D} 664$ & 1.64 & 0.5 & 0.1 \\
\hline
\end{tabular}

Brake thermal efficiency (BTE) is defined as the ratio of brake power to the heat supplied. Figure 4 shows the variation of the BTE at different LPG energy share. It is observed that the BTE of the MOB is lower than diesel in sole fuel mode (zero LPG energy share). This is due to the slightly higher viscosity and lower volatility of the $\mathrm{MOB}$, which results in a higher ignition delay and lower BTE. In dual fuel mode, BTE decreases at the injection time of $24^{\circ}$ bTDC and improves when the injection time is 
advanced to $27^{\circ}$ and $30^{\circ}$ bTDC. But at the injection time of $27^{\circ} \mathrm{bTDC}$, the BTE is marginally higher than the diesel and other injection timings. This is due to the improvement in the pre-flame reaction, which results in better combustion and higher BTE. The BTE reaches its maximum value when the LPG energy share is between $30 \%$ and $40 \%$, in LPG+MOB dual fuel mode at the injection time of $27^{\circ} \mathrm{bTDC}$.

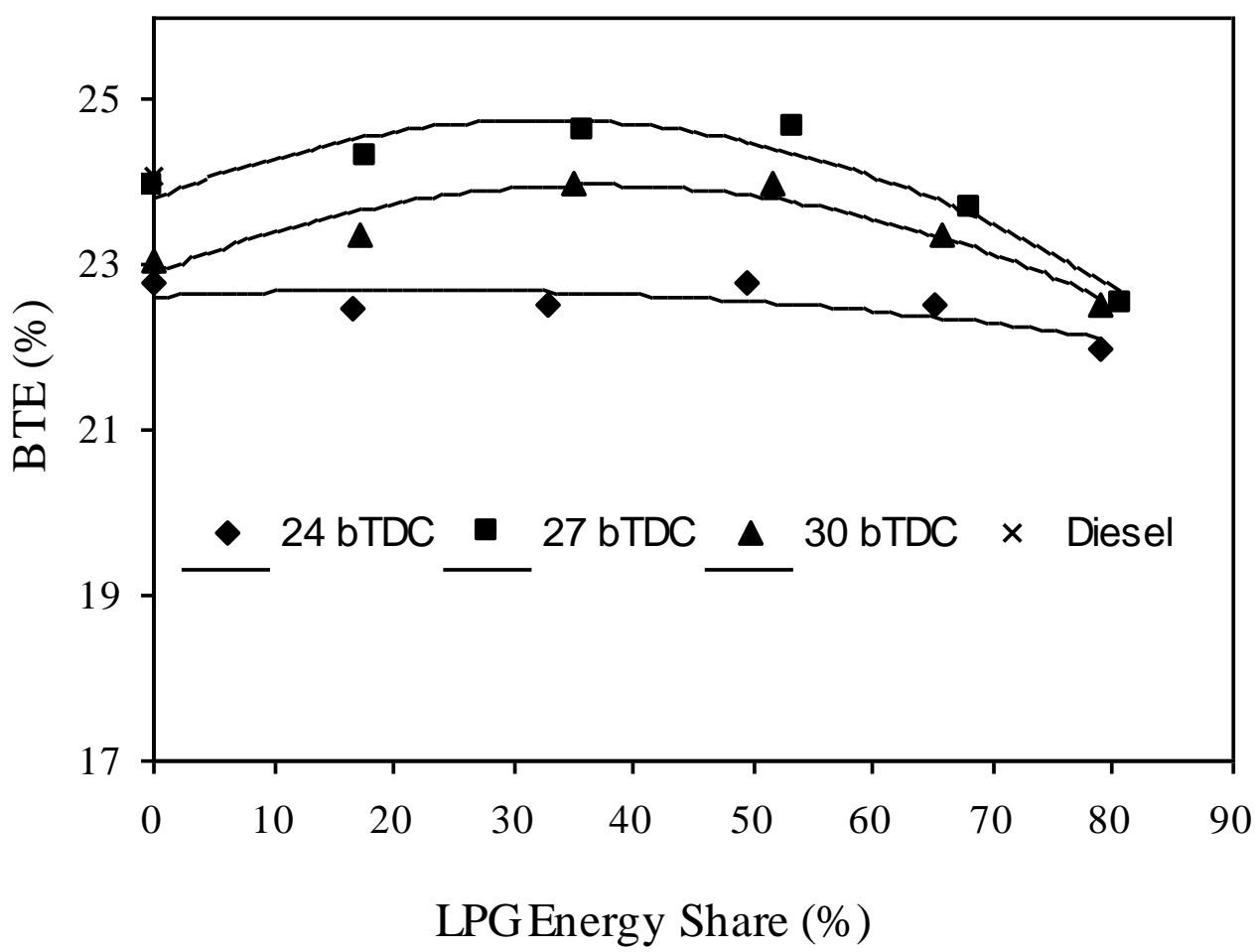

Figure 4. Brake thermal efficiency vs LPG energy share

The variation of CO emission with LPG energy share is shown in Figure 5. It is observed that the diesel results in more $\mathrm{CO}$ than the $\mathrm{MOB}$ in sole fuel mode. This is due to the presence of oxygen in the structure of the MOB which results in lower incomplete products of combustion (CO). From the figure, it is also observed that, as the LPG energy increases, the CO emission decreases and after certain LPG energy share it starts to increase. In dual fuel mode, a higher LPG energy share results in higher CO emission due to the late burning of LPG. In dual fuel mode, liquid fuel (MOB) provides an ignition source for the combustion of the LPG. At higher LPG energy share, the quantity of liquid fuel supplied to the engine is reduced which results in weak combustion of the MOB and late combustion of LPG. This results in higher CO emission. The injection time of $27^{\circ}$ bTDC results in lower $\mathrm{CO}$ emission than other injection timings. At this injection timing, lower $\mathrm{CO}$ emission was observed at an LPG energy share between $30 \%$ and $40 \%$. 


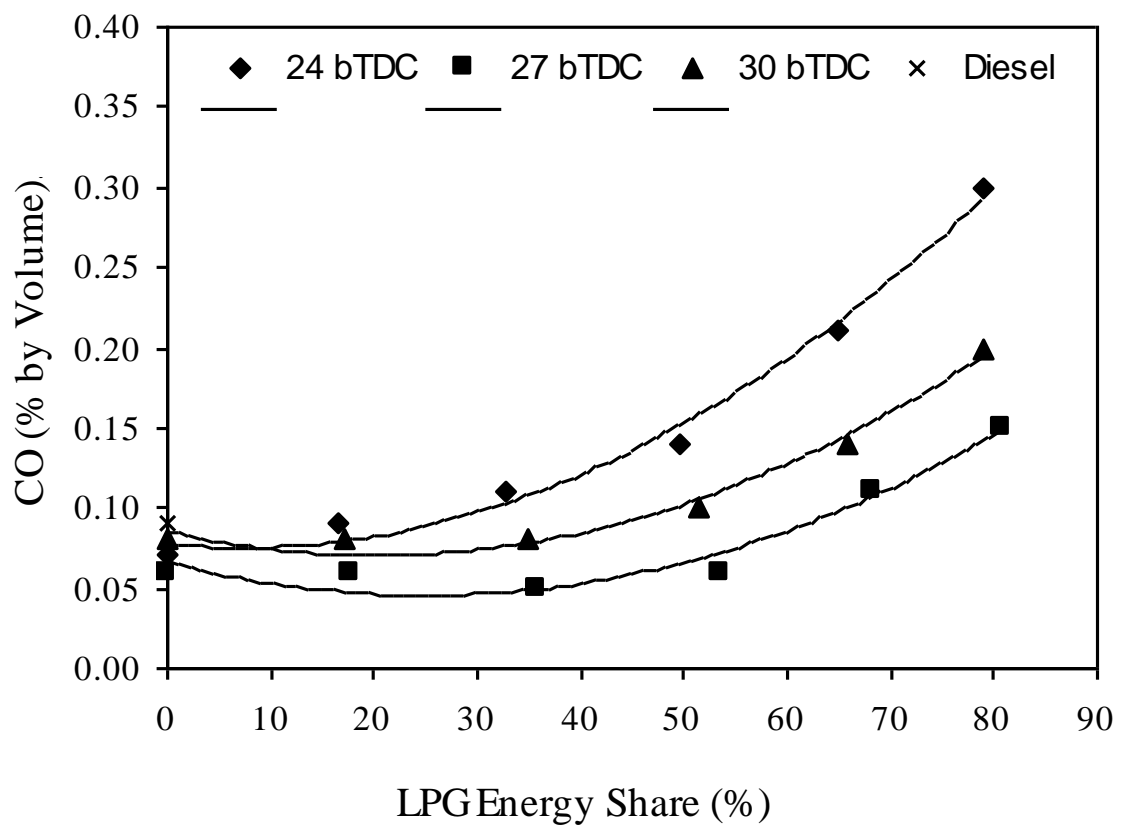

Figure 5. CO vs LPG energy share

Figure 6 shows the variation of unburnt hydrocarbon (UBHC) emission at different LPG energy shares. At the low LPG energy share, the UBHC is low, but as the LPG energy share increases, the UBHC emission also increases. This is due to the late combustion of a large quantity of LPG at higher LPG energy share. Among the injection timings, $27^{\circ} \mathrm{bTDC}$ results in lower UBHC emission. In sole fuel mode, MOB results in lower UBHC emission as compared to diesel.

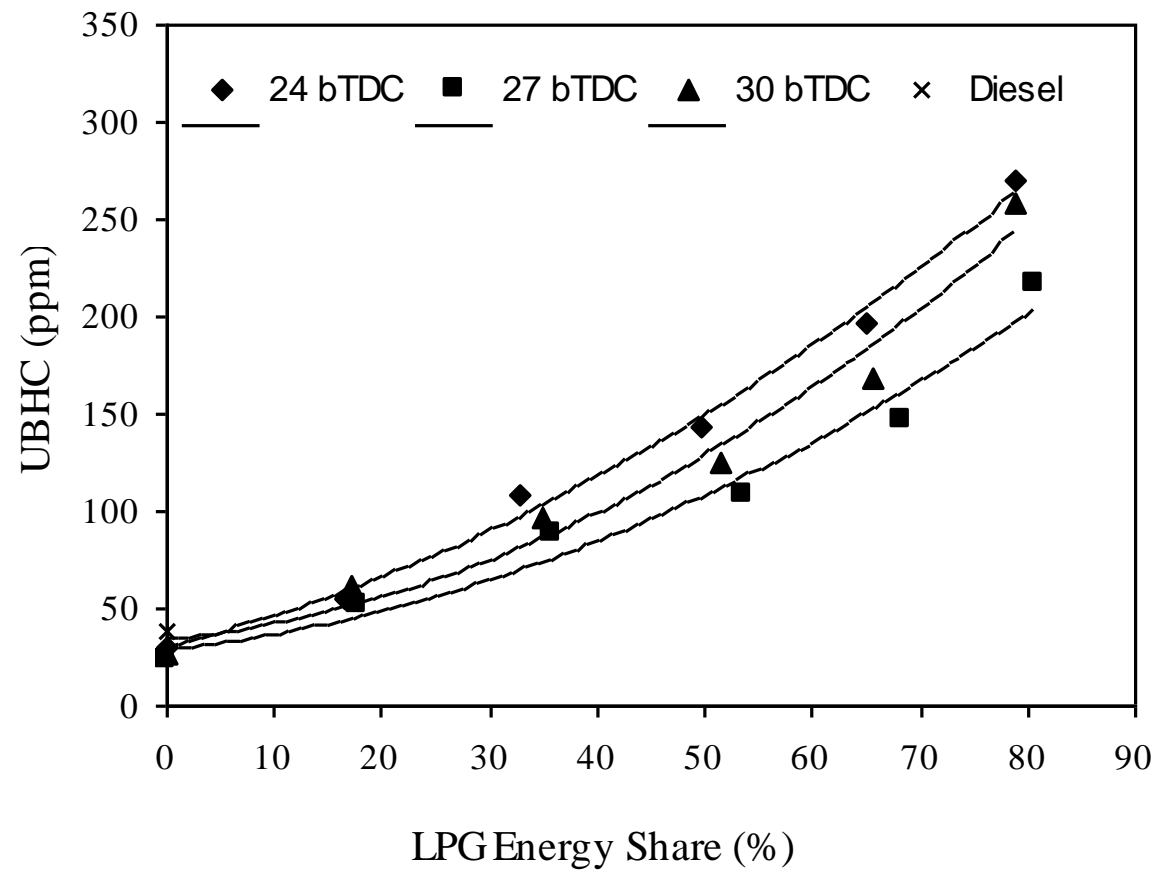

Figure 6. UBHC vs LPG energy share 
The variation of smoke emission with LPG energy share is shown in Figure 7. MOB operation results in lower smoke emission. This is due to the presence of oxygen in the molecular structure of the MOB, which results in better combustion of the fuel and reduces the formation of smoke. From the figure, it is observed that as the LPG energy share increases, the smoke emission decreases. This is due to the molecular structure of LPG which reduces the formation of smoke emission. The injection time of $27^{\circ}$ bTDC results in lower smoke emission. This is due to the better ignition source provided by the MOB, for the combustion of LPG.

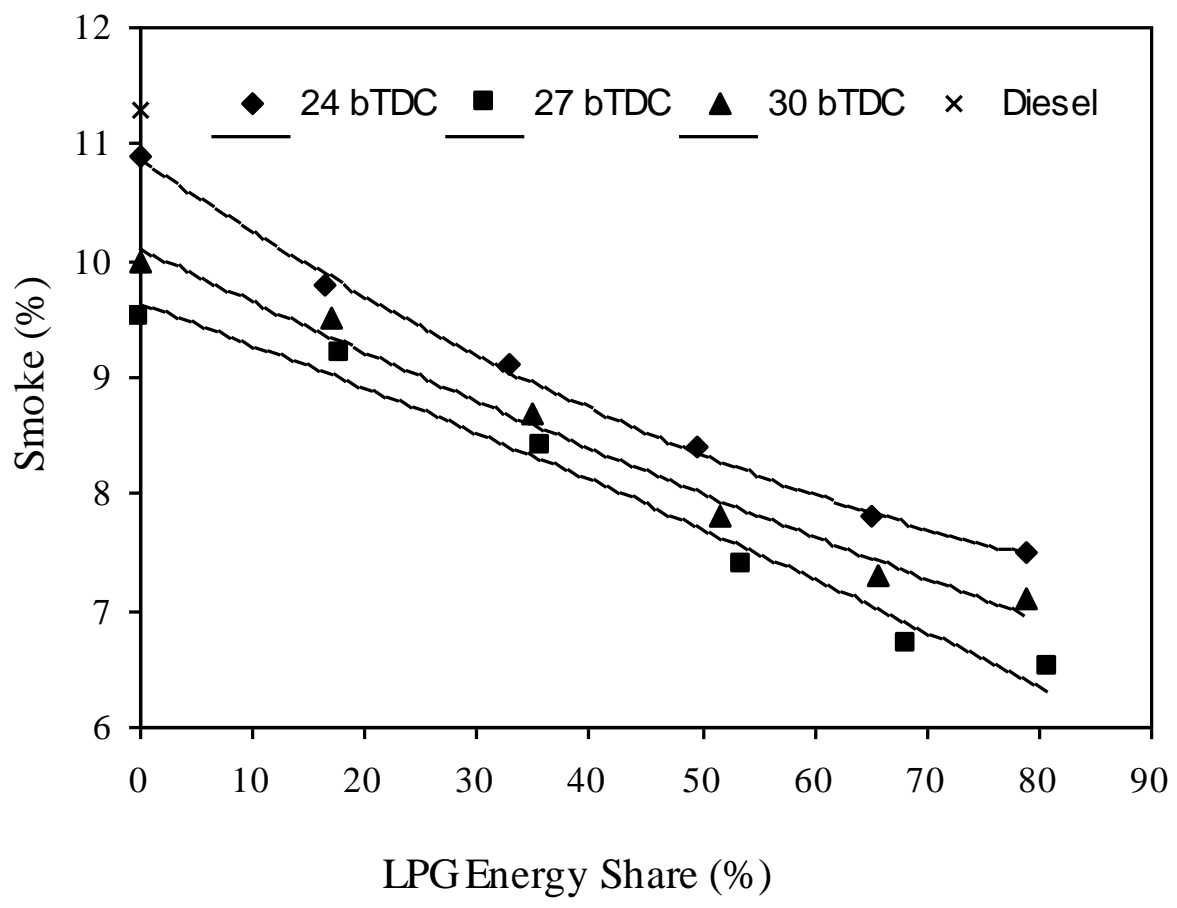

Figure 7. Smoke opacity vs LPG energy share

The variation of oxides of nitrogen (NOx) emission with LPG energy share is shown in Figure 8. The NOx emission depends on the combustion temperature. If the combustion temperature increases, the NOx emission also increases (John, 1988). In sole fuel mode, MOB results in higher NOx emission. This is due to the slightly higher viscosity of the MOB which results in slow combustion. This slow combustion increases the combustion temperature and hence higher NOx emission. From the literature, we observe that a biodiesel operated diesel engine results in higher NOx. From the figure, it is observed that as the LPG energy share increases, the NOx emission decreases. The fumigation of LPG is one of ways of reducing the NOx emission of biodiesel operated diesel engines. The injection time of $24^{\circ} \mathrm{bTDC}$ results in lower NOx emission and $27^{\circ}$ bTDC results in higher NOx emission. The variation of exhaust gas temperature (EGT) with load is shown in Figure 9. Generally, EGT depend upon the combustion temperature. The EGT of the MOB is higher than the diesel. This is due to the better combustion of the fuel. From the higher EGT and NOx of the MOB, we observe that the MOB results in higher combustion temperature. The above results are similar to the results reported in the literature (Sahoo et al., 2009). 


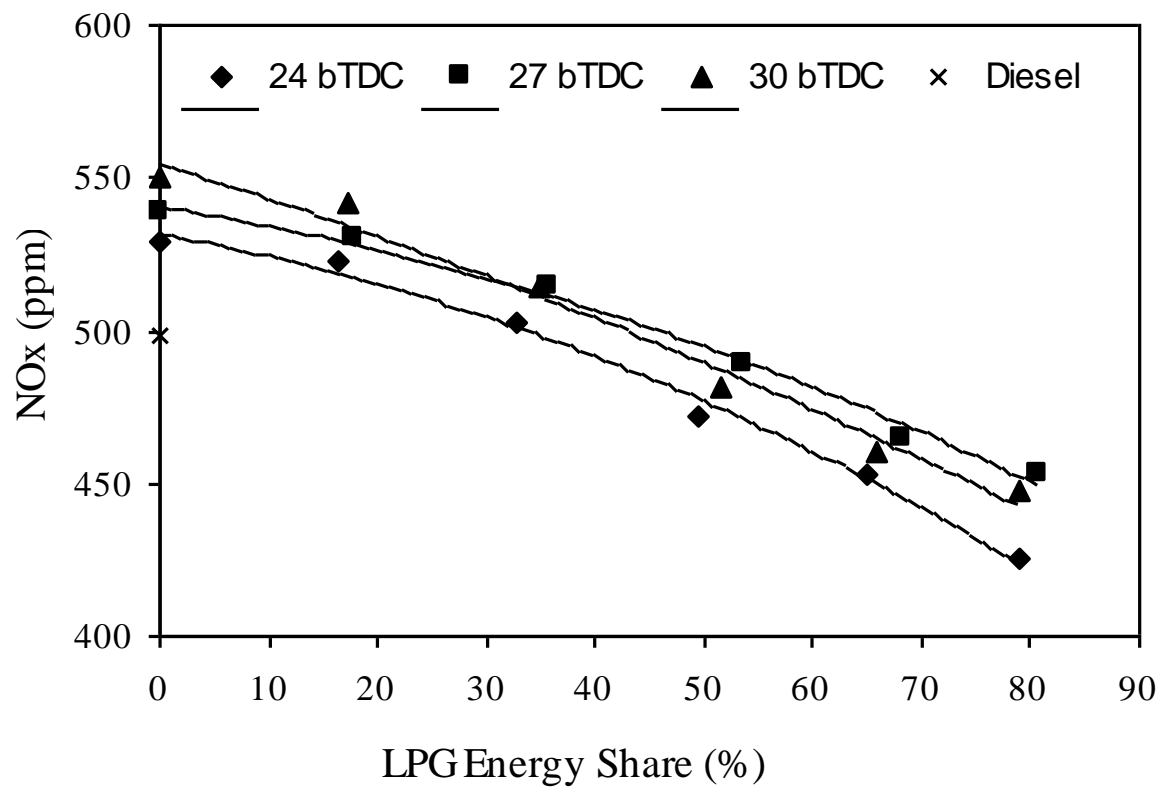

Figure 8. NOx vs LPG energy share

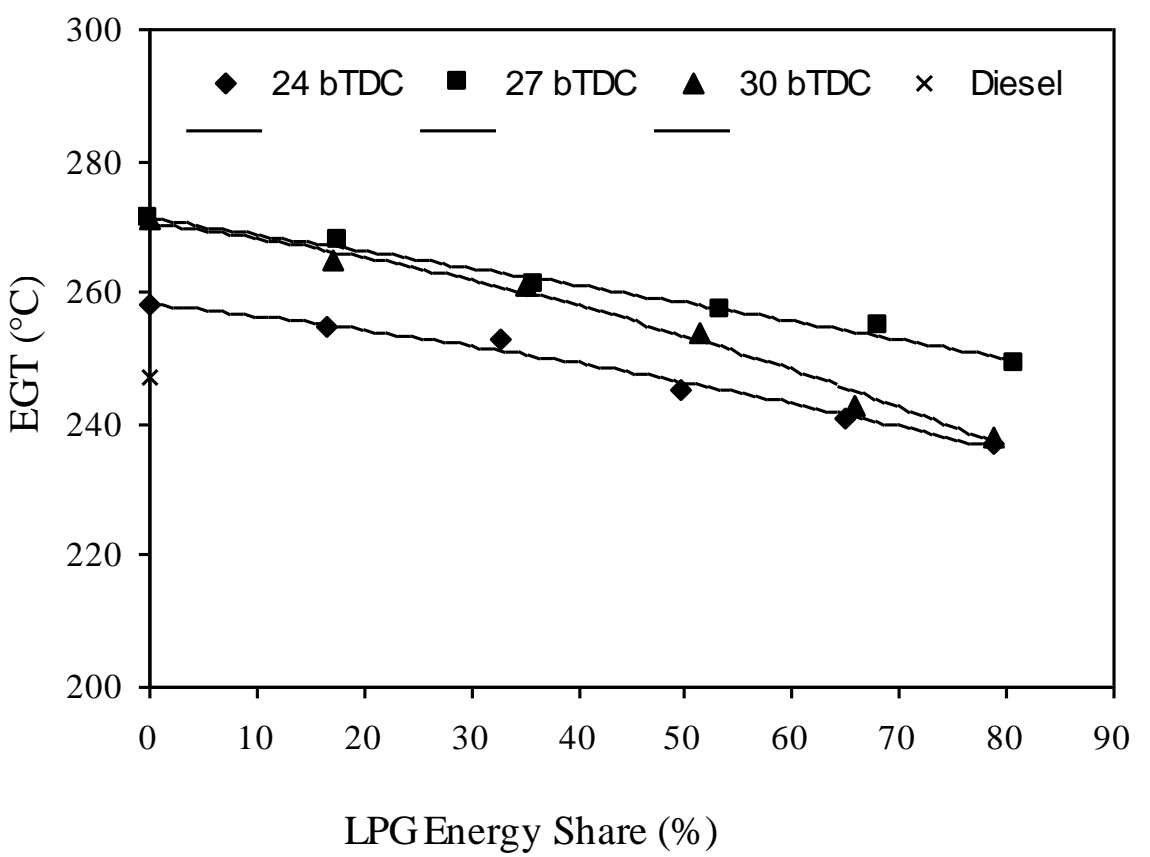

Figure 9. EGT vs LPG energy share

\section{CONCLUSION}

The fuel properties of MOB are closer to those of diesel fuel and satisfy the biodiesel standards of many countries. When MOB was used as sole fuel in the diesel engine, it resulted in lower thermal efficiency and lower exhaust emissions such as CO, UBHC and smoke. In dual fuel mode, the injection timing of $27^{\circ}$ bTDC results in higher efficiency and lower $\mathrm{CO}$, UBHC and smoke emissions as compared to other injection 
timings at part load. But this injection timing results in higher NOx emission than other injection timings. From the experimental results it is concluded that LPG can be fumigated with the air in order to reduce the operating cost and to reduce the smoke and NOx emissions of biodiesel operated diesel engines. Advancing the injection time improves the performance of dual fuel engines operated at part load.

\section{ACKNOWLEDGEMENT}

The financial support by TEQIP (NITK/TEQIP/26/2004), NITK, Surathkal is gratefully acknowledged. The authors thank Mr. Michael and Mr. Bhoja for their help during the engine tests.

\section{REFERENCES}

ASAE. (1982) Vegetable Oil Fuels. Proceedings of the International Conference on Plant and Vegetable Oils as Fuels, August, 2-4, 1982, American Society of Agricultural Engineers, St. Joseph, Mich., USA.

Banapurmath, N.R., Tewari, P.G., Yaliwal,V.S., Kambalimath, S. and Basavarajappa, Y.H. (2009) Combustion Characteristics of a 4-Stroke CI Engine Operated on Honge Oil, Neem and Rice Bran Oils When Directly Injected and Dual Fuelled With Producer Gas Induction. Journal of Renewable Energy, 34(7): 18771884.

Bringi, N.V. (1987) Non-Traditional Oil Seed and Oils of India. New Delhi: Oxford.

Deepak. A., Kumar, L. and Agarwal, A.K. (2008) Performance Evaluation of a Vegetable Oil Fuelled Compression Ignition Engine. Journal of Renewable Energy, 33(6): 1147-1156.

Duke, J.A. and Bagby, M.O. (1982) Comparison of Oilseed Yields: A Preliminary Review in Vegetable Oil Fuels. ASAE.

Holman, J.P. (2006) Experimental Methods for Engineers. New York: McGraw Hill. Jamieson, G.S. (1974) Vegetable Fats and Oils. New York: Reinhold.

Manieniyan, V. and Sivaprakasam, S. (2008) Investigation of Diesel Engine Using Biodiesel (Methyl Ester of Jatropha Oil) for Various Injection Timing and Injection Pressure. SAE Technical Paper, No. 2008-01-1577.

Mariusz, Z. and Geottle, H.J. (1992) Comparative Analysis of the Exhaust Emissions for Vegetable Oil Based Alternative Fuels. SAE Technical Paper, No. 920195.

Mohibbe, A., Amtul, W. and Nahar, N.M. (2005) Prospects and Potential of Fatty Acid Methyl Esters of Some Non-Traditional Seed Oils for Use as Biodiesel in India. Journal of Biomass and Bioenergy, 29: 293-302.

Monyem. A., Van Gerpen, J.H. and Canakci, M. (2001) The Effect of Timing and Oxidation on Emissions From Biodiesel Fueled Engines. Transactions of the ASAE, 44(1): 35-42.

Nwafor, O.M.I. (2005) Effect of Advanced Injection Timing on the Performance of Natural Gas in Diesel Engine. Journal of Sadhana, 25(1): 11-20.

Puhan, S., Vedaraman,N., Sankaranarayanan,G., Boppana, V. and Ram, B. (2005) Performance and Emission Study of Mahua Oil Ethyl Ester in a 4-Stroke 
Natural Aspirated Direct Injection Diesel Engine. Journal of Renewable Energy, 30(8): 1269-1278.

Raheman, H. and Ghadge, S.V. (2007) Performance of Compression Ignition Engine With Mahua (Madhuca Indica) Biodiesel. Journal of Fuel, 86(16): 2568-2573.

Ramadhas, A.S. Jayaraj, S. and Muraleedharan, C. (2004) Use of Vegetable Oils as IC Engines Fuels - A Review. Journal of Renewable Energy, 29: 727-742.

Ramadhas, A.S., Muraleedharan. C. and Jayaraj, S. (2005) Characterization and Effect of Using Rubber Seed Oil as Fuel in the Compression Ignition Engines. Journal of Renewable Energy, 30: 795-803.

Sahoo, B.B., Sahoo, U.K. and Saha, U.K. (2009) Effect of Engine Parameters and Type of Gaseous Fuel on the Performance of Dual-Fuel Gas Diesel EnginesA Critical Review, Journal of Renewable and Sustainable Energy Reviews, 13(6-7): 1151-1184.

Subramanian, K.A., Singal, S.K., Saxena, M. and Singhal, S. (2005) Utilization of Liquid Biofuels in Automotive Diesel Engines: An Indian Perspective. Journal of Biomass and Bioenergy, 29: 65-72.

\section{NOMENCLATURE}

$\begin{array}{ll}\text { MO } & \text { Mahua oil } \\ \text { LPG } & \begin{array}{l}\text { liquefied petroleum gas } \\ \text { million metric tonnes }\end{array} \\ \text { MMT } & \begin{array}{l}\text { carbon monoxide } \% \text { by volume } \\ \text { CO }\end{array} \\ \text { UBHC } & \text { unburnt hydrocarbon ppm } \\ \text { NOx } & \text { oxides of nitrogen ppm } \\ \text { bTDC } & \text { before top dead centre } \\ \text { BTE } & \text { brake thermal efficiency } \% \\ \text { EGT } & \text { exhaust gas temperature }{ }^{\circ} \mathrm{C}\end{array}$

